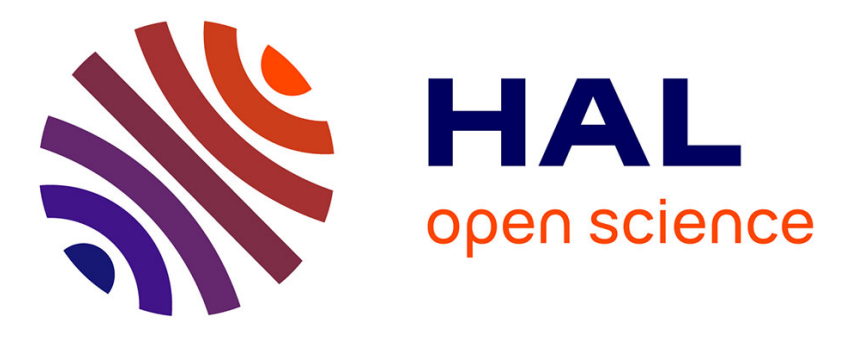

\title{
NMR structural elucidation of dehydrodimers resulting from oxidation of 5-O-caffeoylquinic acid in an apple juice model solution
}

Claudia Mariana Castillo-Fraire, Sandrine Pottier, Arnaud Bondon, Erika Salas, Stéphane Bernillon, Sylvain Guyot, Pascal Poupard

\section{To cite this version:}

Claudia Mariana Castillo-Fraire, Sandrine Pottier, Arnaud Bondon, Erika Salas, Stéphane Bernillon, et al.. NMR structural elucidation of dehydrodimers resulting from oxidation of 5-O-caffeoylquinic acid in an apple juice model solution. Food Chemistry, 2022, Food Chemistry, 372, pp.131117. 10.1016/j.foodchem.2021.131117 . hal-03349274

\section{HAL Id: hal-03349274 \\ https://hal.inrae.fr/hal-03349274}

Submitted on 20 Sep 2021

HAL is a multi-disciplinary open access archive for the deposit and dissemination of scientific research documents, whether they are published or not. The documents may come from teaching and research institutions in France or abroad, or from public or private research centers.
L'archive ouverte pluridisciplinaire HAL, est destinée au dépôt et à la diffusion de documents scientifiques de niveau recherche, publiés ou non, émanant des établissements d'enseignement et de recherche français ou étrangers, des laboratoires publics ou privés.

$$
\text { Copyright }
$$




\section{Journal Pre-proofs}

NMR structural elucidation of dehydrodimers resulting from oxidation of 5-

$O$-caffeoylquinic acid in an apple juice model solution

Claudia Mariana Castillo-Fraire, Sandrine Pottier, Arnaud Bondon, Erika

Salas, Stéphane Bernillon, Sylvain Guyot, Pascal Poupard

PII:

S0308-8146(21)02123-3

DOI:

https://doi.org/10.1016/j.foodchem.2021.131117

Reference:

FOCH 131117

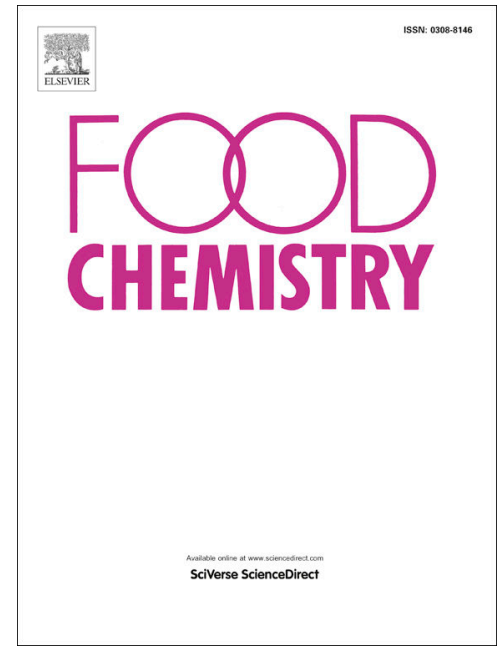

To appear in:

Food Chemistry

Received Date:

10 March 2021

Revised Date:

13 August 2021

Accepted Date:

8 September 2021

Please cite this article as: Castillo-Fraire, C.M., Pottier, S., Bondon, A., Salas, E., Bernillon, S., Guyot, S., Poupard, P., NMR structural elucidation of dehydrodimers resulting from oxidation of 5-O-caffeoylquinic acid in an apple juice model solution, Food Chemistry (2021), doi: https://doi.org/10.1016/j.foodchem.2021.131117

This is a PDF file of an article that has undergone enhancements after acceptance, such as the addition of a cover page and metadata, and formatting for readability, but it is not yet the definitive version of record. This version will undergo additional copyediting, typesetting and review before it is published in its final form, but we are providing this version to give early visibility of the article. Please note that, during the production process, errors may be discovered which could affect the content, and all legal disclaimers that apply to the journal pertain.

(C) 2021 Elsevier Ltd. All rights reserved. 
3 Claudia Mariana Castillo-Fraire a,c, , Sandrine Pottier d,e, Arnaud Bondon d,e, Erika Salas ${ }^{\text {f }}$, Stéphane

4 Bernillon , Sylvain Guyot a,c,*, Pascal Poupard b,c,

5 a INRAE UR BIA - Polyphenols, Reactivity, Processes, F-35653, Le Rheu, France

$6 \quad$ b IFPC (French Institute for Cider Production), F-35653, Le Rheu, France

$7 \quad$ c UMT ACTIA Nova ${ }^{2}$ Cidre, F-35653, Le Rheu, France

$8 \quad$ d Univ Rennes 1, COrInt, ISCR UMR CNRS 6226, Rennes, France

9 e Univ Rennes 1, Plateforme PRISM, SFR UMS CNRS 3480, INSERM 018, Biosit, Rennes, France

$10 \mathrm{f}$ Facultad de Ciencias Químicas, Universidad Autónoma de Chihuahua, Circuito Universitario s/n, 11 Campus Universitario No. 2, CP 31125, Chihuahua, México

12 g UMR1332 Biologie du Fruit et Pathologie, INRAE, Université de Bordeaux, Centre INRAE de 13 Nouvelle Aquitaine-Bordeaux, Villenave d'Ornon, France

* Corresponding author at INRAE UR1268 BIA - Polyphenols, Reactivity, Processes, F-35653, Le Rheu, France. E-mail address: sylvain.guyot@inrae.fr (S. Guyot)

17 Keywords: phenolic compounds, CQA dehydrodimers, chlorogenic acid, PPO, caffeicin

\section{ABSTRACT}

During apple juice and cider-making processes, phenolic compounds undergo enzymatic oxidation. 5-O-caffeoylquinic acid (CQA) is one of the major hydroxycinnamic acid derivatives and it is the preferential substrate for polyphenol oxidase (PPO) in apple juices. Consequently, CQA dehydrodimers (MW $706 \mathrm{Da}$ ) are among the main products resulting from CQA oxidation.

CQA dehydrodimers were previously synthesized in a biomimetic apple juice model solution. Following their purification and characterization using UV-Visible spectra and mass spectrometry, the structures of seven CQA dehydrodimers were elucidated using ${ }^{1} \mathrm{H}$ and ${ }^{13} \mathrm{C}$ oneand two-dimensional NMR spectroscopy. Six of them exhibited dihydrobenzofuran, benzodioxane, or dihydronaphtalene skeletons, which are caffeicin-like structures. Interestingly, 


\section{Introduction}

Chlorogenic acids (CGA) are a group of phenolic acids that correspond to hydroxycinnamic acids esterified by a quinic acid moiety. These widespread compounds are present in plants, fruits, and vegetables, and are characteristic compounds in coffee beans, tea, maté, blueberries, cherries, plums, pears, apples, spinach, and potato tubers (Clifford, 1999, 2000). CGA are known to have bioactive properties such as antioxidant, free radical-scavenging, antibacterial, and antidiabetic properties, as well as neuroprotective activity (Bao et al., 2018; Naveed et al., 2018). Regarding apple and applederived products, the major hydroxycinnamic acid derivative is 5 - $O$-caffeoylquinic acid (CQA). Depending on the apple variety, CQA concentrations range from 200 to $1000 \mathrm{mg} / \mathrm{L}$ in apple juices (Guyot et al., 2008).

During the first step of apple juice production (crushing, pressing), polyphenols come into contact with polyphenol oxidase (PPO). In this step, CQA, the preferential substrate for PPO, can be oxidised into its corresponding ortho-quinone in presence of oxygen. This highly reactive species can be involved in different reaction pathways leading to the formation of a multiplicity of neoformed molecules (Poupard et al., 2008). However, the detailed structures and properties of these oxidation products are yet little known.

Oxidation products have been explored in synthetic solutions using caffeic acid as a model compound (Cilliers \& Singleton, 1991; Fulcrand et al., 1994; Pati et al., 2006; Weber et al., 2019). Some of these oxidised products have been characterised using several techniques: UV-Visible spectra, (Cilliers \& Singleton, 1991; Fulcrand et al., 1994; Pati et al., 2006), mass spectrometry (Pati et al., 2006), and NMR (Cilliers \& Singleton, 1991; Fulcrand et al., 1994). Their characterization has highlighted that they are mainly dehydrodimers resulting from oxidative coupling whose linkage could involve the aromatic ring and/or the double bond of the propenoic acid chain. Most of them have been classified 

as caIreicin and correspona to ainyarobenzoruran, ainyarobenzoaioxan, or ainyaronapntaiene types

In apple juice, caffeoylquinic acid oxidation products were first detected using LC/MS analyses (Bernillon et al., 2004). These compounds were then synthesized in an apple juice model solution. LC/MS analyses confirmed the molecular weight of $706 \mathrm{Da}$, suggesting that these compounds correspond to oxidative coupling between two CQA molecules (Castillo-Fraire et al., 2019; WongPaz et al., 2015). Their tanning properties have been explored previously, highlighting a specific interaction with certain families of salivary proteins (Castillo-Fraire et al., 2021).

In our previous research, sufficient quantities of CQA oxidation products were synthesized enzymatically for purification on a milligram scale. Centrifugal Partition Chromatography (CPC) was optimised to fractionate these CQA dehydrodimers (Castillo-Fraire et al., 2019). After preparative/semi-preparative HPLC, ten CQA dehydrodimers with a chromatographic purity higher than $85 \%$ were successfully recovered (Castillo-Fraire et al., 2019).

In this work, we present the structure elucidation of seven of these CQA dehydrodimers using Nuclear Magnetic Resonance (NMR).

\section{Material and Methods}

\subsection{Chemicals and enzymes}

5-O-caffeoylquinic acid (CQA) was obtained from Sigma-Aldrich (St. Louis, MO, USA) and the crude extract of polyphenol oxidase (PPO) was prepared in our laboratory as described previously (Le Bourvellec et al., 2004). HPLC-grade solvents for the purification of the CQA oxidation products (Castillo-Fraire et al., 2019) and methanol for the NMR analyses were purchased from Eurisotop (Saint-Aubin, France).

\subsection{Synthesis and purification of CQA oxidation products}

The complete procedure has been described in detail in a previous study published recently (CastilloFraire et al., 2019). Briefly, CQA dehydrodimers were synthesized by enzymatic oxidation (PPO) of 
Journal Pre-proofs

CQA in a model solution (Figure 1). I ne remaining CQA was eliminated using Centrirugal rartition Chromatography (CPC) performed in Elution-Extrusion Counter Current Chromatography (EECCC) mode. Finally, purification was sharpened using preparative/semi-preparative HPLC.

The ten CQA dehydrodimers were eluted between 14 min and $46 \min (10-33 \%$ ACN), suggesting a wide dispersion of polarity. The polarity of most of the compounds was lower than their precursors, except for 705-1 and 705-1.1 that were eluted before CQA in the LC/MS analysis. The compound number indicates the order of elution.

\subsection{NMR analyses}

To elucidate their structures, seven CQA dehydrodimers (705-1, 705-1.1, 705-2, 705-3, 705-4, 7055, and 705-6) were analysed using NMR. Samples were dissolved in deuterated methanol ( $\left.\mathrm{CD}_{3} \mathrm{OD}\right)$. NMR spectra were recorded at $298 \mathrm{~K}$ and measurements were carried out on a Bruker AVANCE 500 spectrometer (Bruker, Wissembourg, France) with a Triple Resonance (TCI) $5 \mathrm{~mm}$ cryoprobe $\left({ }^{1} \mathrm{H}\right.$, $\left.{ }^{13} \mathrm{C},{ }^{15} \mathrm{~N}\right)$. The chemical shifts were attributed using 2D Homo-nuclear and Hetero-nuclear spectra: DQF-COSY, TOCSY, edited ${ }^{13} \mathrm{C}-\mathrm{HSQC},{ }^{13} \mathrm{C}-\mathrm{HSQC}-\mathrm{TOCSY}$, and ${ }^{13} \mathrm{C}$-IMPACT-HMBC. Standard pulse sequences from the Bruker database were used. Chemical shifts were expressed as ppm and the spectra were processed using Topspin software.

\section{Results and discussion}

\subsection{NMR analyses}

In a previous study based on UV-Visible spectra and $\mathrm{MS}^{\mathrm{n}}$ spectrometry, three hypothetical structures were proposed for 9 out of the 10 dehydrodimers purified (Castillo-Fraire et al., 2019). In the present study, NMR spectrometry confirmed these structural hypotheses. In addition, NMR was successfully used to propose two novel structural hypotheses. Table 1 shows ${ }^{1} \mathrm{H}$ proton and ${ }^{13} \mathrm{C}$ carbon chemical shifts for the seven compounds analysed. A dihydronaphtalene-type structure (Figure 4) was proposed for compounds 705-1 and 705-1.1, a dihydrobenzofuran-type structure (Figure 2) for dehydrodimers 
As dehydrodimer 705-2 presented a completely different $\mathrm{MS}^{\mathrm{n}}$ fragmentation and UV-Visible spectrum compared to the other CQA dehydrodimers, no hypothetical structure was proposed for this compound in our previous study (Castillo-Fraire et al., 2019). NMR spectrometry analyses were necessary to elucidate its structure.

\subsubsection{Structure elucidation of the dihydrobenzufuran-type dehydrodimers}

112 These compounds presented UV-vis spectra with a $\lambda \max$ at $327 \mathrm{~nm}$ (Castillo-Fraire et al., 2019). The

113 detailed structure of products 705-3 and 705-4 (Figure $2 \mathrm{~A}$ ) was elucidated from the ${ }^{1} \mathrm{H}$ and ${ }^{13} \mathrm{C}$ NMR 114 spectra. The chemical shifts of the carbon and proton atoms are presented in Table 1. The structural 115 analyses of 705-3 and 705-4 have been discussed in a previous paper (Castillo-Fraire et al., 2019). $116 \mathrm{MS}^{\mathrm{n}}$ fragmentation highlighted that they likely correspond to two CQA dehydrodimer isomers with 117 a dihydrobenzofuran moiety. The $\mathrm{MS}^{\mathrm{n}}$ transitions for $705-3$ and $705-4$ were $705 \rightarrow 513 \rightarrow 339 \rightarrow 295$ 118 (Castillo-Fraire et al., 2019). These compounds are analogues of caffeic acid oxidation products 119 (caffeicin F) already described by Cilliers and Singleton (1991).

120 In the following paragraph, all ${ }^{1} \mathrm{H}$ and ${ }^{13} \mathrm{C}$ chemical shifts are given for isomer $705-3$. The 121 corresponding chemical shifts for isomer 705-4 are listed in Table 1.

122 The ${ }^{13} \mathrm{C}$ NMR signal at $167.09 \mathrm{ppm}$ was used as a starting point for the structure elucidation. It corresponds to a strongly deshielded carbon consistent with an ester group. Moreover, the HMBC spectrum showed a clear correlation of this carbon $(167.09 \mathrm{ppm})$ with two adjacent protons showing 125 a large coupling constant ${ }^{2} \mathrm{~J}(15.9 \mathrm{~Hz})$ consistent with $\alpha-\beta$ ethylene protons. This carbon $(167.09 \mathrm{ppm})$ was thus identified as $\mathrm{C} 9$ (Figure 2A) and the two protons at $7.62 \mathrm{ppm}$ and $6.35 \mathrm{ppm}$ were attributed 
$129116.06,116.62,114.78,167.09 \mathrm{ppm})$. On the ${ }^{1} \mathrm{H}-{ }^{13} \mathrm{C}$ HSQC spectrum, carbons $\mathrm{C} 7$ and $\mathrm{C} 8$ correlated 130 with $\mathrm{H} 7$ and $\mathrm{H} 8$ were observed at $145.27 \mathrm{ppm}$ and $114.78 \mathrm{ppm}$, respectively. The signal at 128.45 131 ppm was attributed to the quaternary carbon $\mathrm{C} 1$ (no correlation on ${ }^{1} \mathrm{H}-{ }^{13} \mathrm{C}$ HSQC spectrum).

132 On the ${ }^{1} \mathrm{H}-{ }^{13} \mathrm{C}$ HMBC spectrum, the ${ }^{13} \mathrm{C}$ signals of carbons $\mathrm{C} 2$ and $\mathrm{C} 6$ were detected at $116.06 \mathrm{ppm}$ 133 and $116.62 \mathrm{ppm}$, respectively. The distinction between these two carbons was based on the fact that 134 only carbon C6 (116.62 ppm) was correlated to a moderately deshielded proton (4.37 ppm). From the ${ }^{1} \mathrm{H}-{ }^{13} \mathrm{C}$ HSQC spectrum, the signals at 7.06 and $7.21 \mathrm{ppm}$ could be attributed to $\mathrm{H} 2$ and $\mathrm{H} 6$, respectively. Proton $\mathrm{H} 2(7.06 \mathrm{ppm})$ was also correlated to ${ }^{13} \mathrm{C}$ signals at $141.64 \mathrm{ppm}$ and $149.36 \mathrm{ppm}$ corresponding to carbons $\mathrm{C} 3$ and $\mathrm{C} 4$. The ${ }^{13} \mathrm{C}$ signal at $149.36 \mathrm{ppm}$ was attributed to carbon $\mathrm{C} 4$ as it is the only carbon showing an expected correlation with $\mathrm{H} 6$. Then, the ${ }^{13} \mathrm{C}$ signal at $141.64 \mathrm{ppm}$ was attributed to $\mathrm{C} 3$.

Proton $\mathrm{H} 6(7.21 \mathrm{ppm})$ on the ${ }^{1} \mathrm{H}-{ }^{13} \mathrm{C}$ HMBC spectrum was correlated to a weakly deshielded carbon at $55.65 \mathrm{ppm}$ and the ${ }^{1} \mathrm{H}-{ }^{13} \mathrm{C}$ HSQC spectrum revealed that this carbon at $55.65 \mathrm{ppm}$ was linked to the moderately deshielded proton at $4.37 \mathrm{ppm}$. The latter proton and carbon were thus temporarily attributed to the 8 ' position. According to the ${ }^{1} \mathrm{H}^{13}{ }^{13} \mathrm{C} \mathrm{HMBC}$ spectrum, this proton (H8') was correlated to six carbons. The most deshielded one $(170.57 \mathrm{ppm})$ was attributed to C9', which is consistent with an ester group. The latter carbon (C9') was correlated to a ${ }^{1} \mathrm{H}$ signal at $6.05 \mathrm{ppm}$, which could be temporarily attributed to H7'. Indeed, this proton (H7') was also correlated to six other carbons $(55.65,112.58,117.34,126.20,131.78$, and $149.36 \mathrm{ppm})$ (Figure 2B). Among them, three corresponded to quaternary carbons $(126.20,131.78$, and $149.36 \mathrm{ppm})$. Only one carbon (131.78 ppm) was correlated to three aromatic protons $(6.79,6.79$, and $6.86 \mathrm{ppm})$ allowing its identification 150 as $\mathrm{Cl}^{\prime}$. The signals of the three aromatic protons were consistent with a catechol group. Proton $\mathrm{H} 2$ ' 151 was unambiguously identified at $6.86 \mathrm{ppm}$ and a doublet with a small ${ }^{3} \mathrm{~J}$ coupling constant $(1.5 \mathrm{~Hz})$ was observed. Even if the signals of protons H6' and H5' overlapped at $6.79 \mathrm{ppm}$, they were assigned 
Dased on tneir coupıng constants. Ho presented two coupıng constants ( $8.1 \mathrm{HZ}$ and $1 . \mathrm{J}$ HZ) and HJ

154 only one $(8.1 \mathrm{~Hz})$. In addition, the whole signal integration of this zone (from 6.76 to $6.80 \mathrm{ppm}$ ) was

155 consistent with the signal of two protons. The corresponding carbons C2', C5', and C6' were 156 attributed to chemical shifts at $112.58,114.97$, and $117.34 \mathrm{ppm}$, respectively, according to the ${ }^{1} \mathrm{H}-{ }^{13} \mathrm{C}$ 157 HSQC spectrum. The attribution of proton $\mathrm{H}^{\prime}$ ' was confirmed thanks to its correlation with both C2' 158 and $\mathrm{C6}^{\prime}$ unambiguously observed on the ${ }^{1} \mathrm{H}_{-}{ }^{13} \mathrm{C}$ HMBC spectrum. Consequently, the attribution of 159 proton $\mathrm{H}^{\prime}$ ' was also confirmed. Indeed, this proton (H8') was correlated to two carbons already 160 identified (C6 at $116.62 \mathrm{ppm}$ and $\mathrm{C} 4$ at149.36 ppm) and four other carbons $(86.96,126.20,131.78$, 161 and $170.57 \mathrm{ppm}$ ) according to the ${ }^{1} \mathrm{H}-{ }^{13} \mathrm{C}$ HMBC spectrum. 
165 These compounds presented UV-vis spectra with $\lambda$ max close to $291 \mathrm{~nm}$ and $317 \mathrm{~nm}$ (Castillo-Fraire et al., 2019). These spectra are similar to those of the four caffeicin (A-D) identified by Cilliers and Singleton (1991). The detailed structures of products 705-5 and 705-6 (Figure 3A) were elucidated from the ${ }^{1} \mathrm{H}$ and ${ }^{13} \mathrm{C}$ NMR spectra. The chemical shifts of the ${ }^{13} \mathrm{C}$ and ${ }^{1} \mathrm{H}$ atoms are presented in Table 1. The structural analyses of 705-5 and 705-6 have been discussed in a previous paper (Castillo-Fraire et al., 2019). $\mathrm{MS}^{\mathrm{n}}$ fragmentation revealed that they likely correspond to two CQA dehydrodimer isomers presenting a dihydrobenzodioxane skeleton. The $\mathrm{MS}^{\mathrm{n}}$ transitions for compounds $705-5$ and $705-9$ were $705 \rightarrow 513 \rightarrow 339 \rightarrow 161$ (Castillo-Fraire et al., 2019). These compounds are analogues of caffeic acid oxidation products already described by Cilliers and Singleton (1991).

In the following paragraph, all ${ }^{1} \mathrm{H}$ and ${ }^{13} \mathrm{C}$ chemical shifts are given for isomer 705-5. The corresponding chemical shifts for isomer 705-6 are listed in Table 1.

The ${ }^{13} \mathrm{C}$ NMR signal at $169.1 \mathrm{ppm}$ was used as a starting point for the structure elucidation. It corresponded to a strongly deshielded carbon consistent with an ester group. Moreover, the ${ }^{1} \mathrm{H}-{ }^{13} \mathrm{C}$ HMBC spectrum showed a clear correlation of this carbon (169.1 ppm) with two adjacent protons presenting a large coupling constant ${ }^{2} \mathrm{~J}(15.9 \mathrm{~Hz})$ consistent with $\alpha-\beta$ ethylene protons. This carbon (169.1 ppm) was thus identified as C9 (Figure 3A) and the two protons at $7.6 \mathrm{ppm}$ and $6.4 \mathrm{ppm}$ were attributed to $\mathrm{H} 7$ and $\mathrm{H} 8$. $\mathrm{HMBC}$ correlations allowed $\mathrm{H} 8(6.4 \mathrm{ppm})$ to be unambiguously distinguished from H7 (7.6 ppm). Indeed, the latter was the only one showing HMBC correlations with two carbons (118.8 and $124.5 \mathrm{ppm}$ ) that were correlated to aromatic protons on the ${ }^{1} \mathrm{H}-{ }^{13} \mathrm{C}$ HSQC NMR spectrum assigned as H2 (7.26 ppm, d, $2 \mathrm{~Hz}$ ) and $\mathrm{H} 6$ (7.2 ppm, dd, 8.5 and $2 \mathrm{~Hz}$ ), respectively. The corresponding carbons $\mathrm{C} 7$ and $\mathrm{C} 8$ of protons $\mathrm{H} 7$ and $\mathrm{H} 8$ were at $146.8 \mathrm{ppm}$ and $118.4 \mathrm{ppm}$, respectively. The ${ }^{13} \mathrm{C}$ signal at $130.9 \mathrm{ppm}$ was attributed to the quaternary carbon $\mathrm{C} 1$. 
carbon $\mathrm{C} 4$ as $1 \mathrm{l}$ was tne only carbon snowing an expected correlation witn Ho (/.L ppm). ine ${ }^{17} \mathrm{C}$

190 signal at $145.6 \mathrm{ppm}$ was thus attributed to C3.

191 The ${ }^{1} \mathrm{H}-{ }^{13} \mathrm{C}$ HMBC spectrum showed a correlation between carbon $\mathrm{C} 6$ (124.5 ppm) and another 192 aromatic proton at $7.03 \mathrm{ppm}$ that was assigned as $\mathrm{H} 5(\mathrm{~d}, 8.5 \mathrm{~Hz})$. This proton $\mathrm{H} 5$ was also correlated 193 to two aromatic carbons assigned previously: C3 at $145.6 \mathrm{ppm}$ and C4 at $146.6 \mathrm{ppm}$.

194 Conversely, the ${ }^{13} \mathrm{C}$ NMR signal at $169.5 \mathrm{ppm}$ was used as a starting point for the structure elucidation 195 of the other CQA moiety. It corresponded to a strongly deshielded carbon consistent with an ester 196 group. The ${ }^{1} \mathrm{H}-{ }^{13} \mathrm{C}$ HMBC spectrum showed a clear correlation of this carbon (169.5 ppm) with three 197 protons $(4.9,5.1$, and $5.26 \mathrm{ppm})$. The proton at $5.26 \mathrm{ppm}$ was assigned as H10', as this proton was 198 correlated to the quinic acid part of the CQA moiety. The carbon at $169.5 \mathrm{ppm}$ was thus assigned as 199 C9'. The ${ }^{1} \mathrm{H}_{-}{ }^{13} \mathrm{C}$ HMBC spectrum showed correlation of the proton at $5.1 \mathrm{ppm}$ with six carbons (78.9, $200116.4,121.2,128.7,145.6$, and $169.5 \mathrm{ppm})$. On the ${ }^{1} \mathrm{H}-{ }^{13} \mathrm{C}$ HSQC NMR spectrum, two of them $(116.4$ 201 and $121.2 \mathrm{ppm}$ ) were correlated to aromatic protons at $6.79 \mathrm{ppm}$ and $6.88 \mathrm{ppm}$, corresponding to $\mathrm{H} 2$ ' 202 and $\mathrm{H}^{\prime}$. The ${ }^{13} \mathrm{C}$ signal at $128.7 \mathrm{ppm}$ was attributed to the quaternary carbon $\mathrm{C} 1$ '. Based on these 203 correlations, the two protons at $5.1 \mathrm{ppm}$ and $4.9 \mathrm{ppm}$ were attributed to $\mathrm{H}^{\prime}$ ' and $\mathrm{H} 8$ ', respectively. 204 Their corresponding carbons $\mathrm{C} 7$ ' and $\mathrm{C} 8$ ' were assigned at $78.4 \mathrm{ppm}$ and $78.8 \mathrm{ppm}$ on the ${ }^{1} \mathrm{H}_{-}{ }^{13} \mathrm{C}$ 205 HSQC NMR spectrum.

206 Interestingly, a clear correlation was observed on the HMBC spectrum between H7' (5.1 ppm) and a 207 carbon at $145.6 \mathrm{ppm}$ that was previously assigned as C3. Additionally, a correlation between H8' (4.9 $208 \mathrm{ppm}$ ) and a carbon at $146.6 \mathrm{ppm}$ corresponding to $\mathrm{C} 4$ was observed. These two correlations constitute 209 proof for the elucidation of the dihydrobenzodioxane structure (Figure 3B).

\section{1 .3 Structure elucidation of the dihydronaphtalene-type dehydrodimers}


Inis pair or compounas presented U V-Vis spectra With $A$ max around $318 \mathrm{~nm}$ and $54 \angle \mathrm{nm}$ (Castillo-

213 Fraire et al., 2019). The complete NMR analysis of dehydrodicaffeoyldiquinic acid dimers 705-1 and

214 705-1.1 was used to confirm the structure of dehydrodimers showing a dihydronaphtalene nucleus

215 (Figure 4A) based on the $\mathrm{MS}^{\mathrm{n}}$ fragmentation, as discussed in a previous paper (Castillo-Fraire et al.,

216 2019). The proposed structure was an analogue of caffeicin E resulting from caffeic acid oxidative 217 coupling (Cilliers \& Singleton, 1991). The $\mathrm{MS}^{\mathrm{n}}$ transitions for 705-1 and 705-1.1 were $218705 \rightarrow 513 \rightarrow 339 \rightarrow 229 \mathrm{~nm}$ (Castillo-Fraire et al., 2019).

219 In the following part, the discussion concerns the ${ }^{1} \mathrm{H}$ and ${ }^{13} \mathrm{C}$ attributions for product $705-1$. The same 220 approach can be applied to product 705-1.1 that exhibited the same correlation scheme on the ${ }^{1} \mathrm{H}-{ }^{13} \mathrm{C}$ $221 \mathrm{HMBC},{ }^{1} \mathrm{H}-{ }^{13} \mathrm{C}$ HSQC, and ${ }^{1} \mathrm{H}-{ }^{1} \mathrm{H}$ COSY spectra. All details of chemical shifts and attribution of 222 coupling constants are provided in Table 1.

223 Interestingly, in the present case, the ${ }^{1} \mathrm{H}$ NMR spectrum does not show any deshielded protons that 224 would belong to a free $\alpha-\beta$ ethylenic system exhibiting a large coupling constant close to $16 \mathrm{~Hz}$. This specific two-proton system was clearly observed and discussed before for products $705-3$ and -4 and 705-5 and -6. This suggests that, in the case of 705-1, both ethylene linkages of the caffeoyl moieties 227 have been modified in such a way that they are both involved in oxidative coupling.

228 This observation led us to select as a starting point the only strongly deshielded proton (singlet at 7.65 229 ppm) that also exhibited a clear HMBC correlation with a strongly deshielded carbon (169.2 ppm) 230 consistent with an ester group. The proton was thus assigned as H7 and this deshielded carbon was 231 attributed to C9. Then, carbon C9 clearly showed an HMBC correlation with another much more 232 shielded proton at $3.95 \mathrm{ppm}$ (doublet with $\mathrm{J}=3.4 \mathrm{~Hz}$ ) that was attributed to H8'. Consequently, this 233 coupling constant $(3.4 \mathrm{~Hz}$ ) allowed us to assign proton $\mathrm{H} 7$ ' at $7.47 \mathrm{ppm}$ (doublet, $\mathrm{J}=3.4 \mathrm{~Hz})$ and its 234 corresponding carbon $\mathrm{C}^{\prime}$ ' located at $47.52 \mathrm{ppm}$ using the ${ }^{1} \mathrm{H}^{13} \mathrm{C}$ HSQC spectrum. Noticeably, the $235{ }^{1} \mathrm{H}-{ }^{13} \mathrm{C} \mathrm{HMBC}$ spectrum showed that proton $\mathrm{H} 7$ ' was also correlated with nine carbons (Figure 4B). 


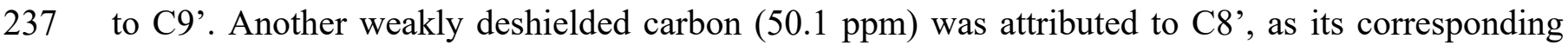
238 proton $\mathrm{H} 8$ ' was located at $3.94 \mathrm{ppm}$ on the ${ }^{1} \mathrm{H}-{ }^{13} \mathrm{C}$ HSQC spectrum. The ${ }^{13} \mathrm{C}$ signals of the other seven 239 carbons were located between $116 \mathrm{ppm}$ and $136 \mathrm{ppm}$, consistent with aromatic or ethylene carbons.

240 Among them, C1', C8, and C6 could be distinguished from the others as they showed HMBC 241 correlations with both $\mathrm{H} 7$ ' and $\mathrm{H} 8$ '. C1' was easily distinguished as it presented typical correlations 242 of an aromatic ABX system in a catechol group. C6 could be distinguished from C8 as only C6 243 exhibited HMBC correlations with three aromatic or ethylene protons, namely H5 (singlet $6.56 \mathrm{ppm}$ ), $244 \mathrm{H} 2$ (singlet, $6.88 \mathrm{ppm}$ ), and H7 (7.65 ppm). In contrast, C8 only showed correlation with one ethylene 245 proton, namely $\mathrm{H} 7$ (7.65 ppm). H5 was distinguished from $\mathrm{H} 2$ as $\mathrm{H} 5$ showed HMBC correlation with 246 C7'.

In contrast to the dihydrobenzofuran and the dihydrobenzodioxane structures, proton $\mathrm{H}^{\prime}$ ' in the dihydronaphtalene structure showed HMBC correlation with both C9 and C9' (ester group).

The complete NMR signal attributions of the protons and carbons belonging to the two catechol groups are not discussed here due to similarities with the structures of products $705-3$ and -4 , and 705-5 and -6 that have already discussed. All these attributions are given in Table 1.

\subsubsection{Structure elucidation of the dehydrodimer presenting a symmetric structure}

254 Although its molecular weight (MW $706 \mathrm{Da}$ ) and the presence of two quinic acid moieties were confirmed by mass spectrometry (Castillo-Fraire et al., 2019), compound 705-2 exhibited very different physicochemical features compared to the other CQA dehydrodimers. For instance, it was the only one showing a specific UV-Visible spectrum with a $\lambda$ max at $282 \mathrm{~nm}$ and no more absorbance in the 300-340 $\mathrm{nm}$ region (Castillo-Fraire et al., 2019). This lack of absorbance at $320 \mathrm{~nm}$ for 705-2 
Ionger present in the aenyaroaimer structure. Interestingıy, tnıs particuiar teature nas already been

261 observed for a dehydrodicaffeic acid oxidation product (Fulcrand et al., 1994).

263 In addition, the ${ }^{1} \mathrm{H}$ NMR spectrum was also original and differed from the other CQA dehydrodimers 264 as it revealed a symmetric structure containing 24 non-hydroxyl protons. The ${ }^{1} \mathrm{H}$ and ${ }^{13} \mathrm{C}$ attributions 265 and chemical shifts are given in Table 1 . The complete $1 \mathrm{D}$ and $2 \mathrm{D}{ }^{1} \mathrm{H}$ and ${ }^{13} \mathrm{C}$ NMR analyses allowed 266 two hypothetical structures A and B to be proposed (Figure 5).

Except for some crucial NMR correlations, the following discussion mainly concerns the "non-prime" numbered moiety of the molecule. Considering the symmetry of the molecule, the argumentation is the same regarding the attribution of the "prime" numbered moiety.

The detailed structure of product 705-2 was elucidated from the ${ }^{1} \mathrm{H}$ and ${ }^{13} \mathrm{C}$ NMR spectra. The ${ }^{1} \mathrm{H}$ NMR spectrum revealed the presence of two aromatic protons at $6.77 \mathrm{ppm}$ and one at $6.83 \mathrm{ppm}$. Their corresponding carbons were observed at $116.9,117.3$, and $121.9 \mathrm{ppm}$, respectively, on the ${ }^{1} \mathrm{H}-{ }^{13} \mathrm{C}$ HSQC NMR spectrum. HMBC correlations allowed C6 to be assigned at 116.9 ppm as this carbon was correlated with the two aromatic protons at $6.77 \mathrm{ppm}(\mathrm{H} 2$ and $\mathrm{H} 5)$. The ${ }^{1} \mathrm{H}-{ }^{13} \mathrm{C}$ HMBC and ${ }^{1} \mathrm{H}-$ ${ }^{13} \mathrm{C}$ HSQC NMR spectra permitted their corresponding carbons C2 and C5 to be assigned at 121.9 ppm and 117.3 ppm, respectively.

Carbon C6 (116.9 ppm) was also correlated with a deshielded proton at $6.27 \mathrm{ppm}$. The ${ }^{1} \mathrm{H}-{ }^{13} \mathrm{C}$ HMBC

278 NMR spectrum showed that this proton has the particularity of being correlated with 7 carbons (55.3, $27973.5,116.9,121.9,131.4,171.4$, and $172.7 \mathrm{ppm})$. Among them, three corresponded to aromatic 280 carbons that were attributed to $\mathrm{C} 6$ at $116.9 \mathrm{ppm}, \mathrm{C} 2$ at $121.9 \mathrm{ppm}$, and the quaternary carbon $\mathrm{C} 1$ at $281131.4 \mathrm{ppm}$. The proton at $6.27 \mathrm{ppm}$ was thus attributed to $\mathrm{H} 7$ (dd, $11 \mathrm{~Hz}$ and $1.7 \mathrm{~Hz}$ ). The ${ }^{1} \mathrm{H}_{-}{ }^{13} \mathrm{C}$ 282 HSQC NMR spectrum allowed the chemical shift of its corresponding carbon C7 at 73.5 ppm to be 283 determined. 
Noticeabiy, proton H/ was correlated with two strongiy desnielded carbons tnat nave a ${ }^{1+} \mathrm{C}$ NIVIK

285 signal at $171.4 \mathrm{ppm}$ and $172.7 \mathrm{ppm}$ consistent with the carbon of ester groups. The ${ }^{13} \mathrm{C}$ signal at 171.4 ppm was attributed to C9 based on its clear HMBC correlation with proton $\mathrm{H} 10$ (4.72 ppm) of the quinic acid moiety through the oxygen atom. In contrast, the carbon at $172.7 \mathrm{ppm}$ showed clear HMBC correlations with four shielded protons (at 1.75, 1.77, 2.53, and $2.57 \mathrm{ppm}$ ) attributed to the two $\mathrm{CH} 2$ groups (H11 and $\mathrm{H} 13$ protons) of the quinic acid moiety. This carbon at 172.7 ppm was attributed to $\mathrm{C} 16$ or $\mathrm{C} 16$ ' for hypothesis $\mathrm{A}$ or $\mathrm{B}$, respectively.

In addition, proton $\mathrm{H} 7(6.27 \mathrm{ppm})$ was correlated to a moderately deshielded carbon at $55.3 \mathrm{ppm}$. The ${ }^{1} \mathrm{H}-{ }^{13} \mathrm{C}$ HSQC NMR spectrum permitted the chemical shift of its corresponding proton (3.89 ppm) to be determined. The ${ }^{1} \mathrm{H}-{ }^{13} \mathrm{C}$ HMBC NMR spectrum showed correlations between this proton (3.89 ppm) and four carbons $(55.3,73.5,131.4$, and $171.4 \mathrm{ppm})$. Among them, the NMR results highlighted the correlation with carbon $\mathrm{C} 7$ at $73.5 \mathrm{ppm}$, the quaternary carbon $\mathrm{C} 1$ at $131.4 \mathrm{ppm}$, and carbon $\mathrm{C} 9$ at $171.4 \mathrm{ppm}$. The proton at $3.89 \mathrm{ppm}$ was thus attributed to $\mathrm{H} 8$. The $\mathrm{H}-\mathrm{H}$ coupling constants of 11 $\mathrm{Hz}$ and $1.7 \mathrm{~Hz}$ measured for proton $\mathrm{H} 8$ (or $\mathrm{H} 8$ ') were the same as those measured for proton $\mathrm{H} 7$ (or H7') (Table 1). These coupling constants correspond to ${ }^{2} \mathrm{~J}$ coupling (between $\mathrm{H} 7$ and $\mathrm{H} 8$ or H7' and $\mathrm{H} 8^{\prime}$ ) and ${ }^{4} \mathrm{~J}$ coupling (between $\mathrm{H} 7$ and $\mathrm{H} 8$ ' or $\mathrm{H} 8$ and $\mathrm{H} 7^{\prime}$ ). This can be considered as proof of the C8-C8'covalent bonding between both CQA moieties.

Another spot also confirmed the symmetric character of the molecule when the ${ }^{1} \mathrm{H}-{ }^{13} \mathrm{C}$ HMBC and HSQC NMR spectra were overlapped. Indeed, the ${ }^{1} \mathrm{H}-{ }^{13} \mathrm{C}$ HMBC spectrum revealed that the proton H8 (3.89 ppm) was correlated with a carbon presenting the same chemical shift at $55.3 \mathrm{ppm}$, proving that $\mathrm{H} 8$ was correlated with carbon $\mathrm{C} 8$ ' of the other CQA moiety. structures showed two free catechol groups and both carboxylic groups of the quinic acid moieties are here included in two additional ester linkages. Neither the NMR analyses nor the $\mathrm{MS}^{\mathrm{n}}$ 
Iragmentation pattern enabied one oI the two proposed nypotnetical symmetric structures to de

309 discarded or favoured.

310 The hypotheses of both structures are based on the fact that the ${ }^{1} \mathrm{H}-{ }^{13} \mathrm{C}$ HMBC spectrum revealed a

311 correlation between $\mathrm{H} 7$ and $\mathrm{C} 16$ or $\mathrm{C}^{\prime} 6^{\prime}$ and these two carbons cannot be distinguished due to the 312 symmetry of the molecule.

313 A mechanism was proposed for these structures (Figure 5), starting with the PPO-catalysed oxidation 314 of CQA leading to the formation of CQA ortho-quinone. This CQA ortho-quinone and another CQA 315 molecule can generate two semiquinone radicals by a reverse disproportionation. Then, radical 316 coupling can take place between carbons C8 and C8' of these semiquinones generating a covalent 317 bond between these two molecules. Finally, a nucleophilic addition step occurs between the C16 (or 318 C16') hydroxyl group and the C7 (or C7') position, followed by re-aromatization to yield the 319 symmetric structure.

320 The particular presence of two catechol groups in this symmetric structure could confer tanning 321 properties to this compound. Indeed, complexation between polyphenols and proteins is dominated mainly by hydrogen bonds and hydrophobic interactions involving the catechol groups of phenolic 323 compounds (de Freitas \& Mateus, 2012). These likely tanning properties could lead to specific 324 interactions regarding salivary proteins and might have an impact on mouthfeel/sensations more or 325 less related to astringency perception (Castillo-Fraire et al., 2021).

\section{Conclusion}

327 In a previous study, CQA dehydrodimers were synthesized in a biomimetic apple juice model solution

328 (Castillo-Fraire et al., 2019). After purification and characterization using UV-Visible spectra and $329 \mathrm{MS}^{\mathrm{n}}$ fragmentation, three hypothetical structures were proposed for nine of the ten 330 dehydrodicaffeoyldiquinic acids (Castillo-Fraire et al., 2019). 
332 spectroscopy. Four different structures were elucidated for dehydrodicaffeoyldiquinic acid 333 compounds. Six of these CQA dehydrodimers corresponded to three different caffeicin-like 334 skeletons: the dihydronaphtalene type for 705-1 and 705-1.1, the dihydrobenzofuran type for 705-3 335 and 705-4, and the dihydrobenzodioxane type for 705-5 and 705-6. Although our NMR data did not 336 completely elucidate the stereochemistry of these molecules, the pairs of CQA oxidation products 337 with the same skeleton are very likely stereoisomers resulting from the asymmetric C7' and C8' 338 carbon centres. In addition, a phenolic structure corresponding to a symmetric dicatechol skeleton 339 was highlighted for the first time as one of the dehydrodicaffeoyldiquinic acids resulting from CQA 340 oxidative coupling.

341 Further studies are needed to better understand the relationships between structure and functional 342 properties, regarding their contribution to organoleptic and nutritional qualities in apple-based 343 beverages.

\section{Funding sources}

346 The authors wish to thank the Mexican Council for Science and Technology (CONACYT) (556831) 347 for their financial support of a student via a graduate scholarship.

\section{Acknowledgments}

349 We are grateful to the P2M2 platform from the GIS Biogenouest (Le Rheu, France) for providing 350 equipment and technical support for the chromatographic analyses.

351 Part of this work was performed using the PRISM core facility (Biogenouest $\mathrm{C}$, UMS Biosit, 352 Université de Rennes 1- Campus de Villejean- 35043 RENNES Cedex, FRANCE). 
Bao, L., Li, J., Zha, D., Zhang, L., Gao, P., Yao, T., \& Wu, X. (2018). Chlorogenic acid prevents

Bernillon, S., Guyot, S., \& Renard, C. M. G. C. (2004). Detection of phenolic oxidation products in

Castillo-Fraire, C. M., Brandao, E., Poupard, P., Le Quére, J.-M., Salas, E., De Freitas, V., Guyot, S., \& Soares, S. (2021). Interactions between polyphenol oxidation products and salivary proteins : Specific affinity of CQA dehydrodimers with cystatins and P-B peptide. Food Chemistry, 343(128496), 1-11. https://doi.org/10.1016/j.foodchem.2020.128496

Castillo-Fraire, C. M., Poupard, P., Guilois-Dubois, S., Salas, E., \& Guyot, S. (2019). Preparative fractionation of 5'-O-caffeoylquinic acid oxidation products using centrifugal partition chromatography and their investigation by mass spectrometry. Journal of Chromatography A, 1592, 19-30. https://doi.org/10.1016/j.chroma.2019.01.071

Cilliers, J. J. L., \& Singleton, V. L. (1991). Characterization of the Products of Nonenzymic Autoxidative Phenolic Reactions in a Caffeic Acid Model System. Journal of Agricultural and Food Chemistry, 39(7), 1298-1303. https://doi.org/10.1021/jf00007a021

Clifford, M. N. (1999). Chlorogenic acids and other cinnamates-nature, occurrence and dietary burden. Journal of the Science of Food and Agriculture, 79(3), 362-372. https://doi.org/10.1002/(SICI)1097-0010(19990301)79 
CIIIIOra, IVI. N. (LUVU). Lnıorogenic acias and otner cinnamates-nature, occurence, aletary buraen, absorption and metabolism. J Sci Food Agric., 80(December 1999), 1033-1043.

de Freitas, V., \& Mateus, N. (2012). Protein/Polyphenol Interactions: Past and Present Contributions. Mechanisms of Astringency Perception. Current Organic Chemistry, 16(351), 724-746. https://doi.org/10.2174/138527212799958002

Fulcrand, H., Cheminat, A., Brouillard, R., \& Cheynier, V. (1994). Characterization of compounds obtained by chemical oxidation of caffeic acid in acidic conditions. Phytochemistry, 35(2), 499505. https://doi.org/10.1016/S0031-9422(00)94790-3

Guyot, S., Bernillon, S., Poupard, P., \& Renard, C. M. G. C. (2008). Multiplicity of Phenolic Oxidation Products in Apple Juices and Ciders, from Synthetic Medium to Commercial Products. In D. Fouad \& L. Vincenzo (Eds.), Recent Advances in Polyphenol Research (pp. 278292). Wiley-Blackwell. https://doi.org/10.1002/9781444302400.ch12

Le Bourvellec, C., Le Quéré, J. M., Sanoner, P., Drilleau, J. F., \& Guyot, S. (2004). Inhibition of Apple Polyphenol Oxidase Activity by Procyanidins and Polyphenol Oxidation Products. Journal of Agricultural and Food Chemistry, 52(1), 122-130. https://doi.org/10.1021/jf034461q

Naveed, M., Hejazi, V., Abbas, M., Kamboh, A. A., Khan, G. J., Shumzaid, M., Ahmad, F., Babazadeh, D., FangFang, X., Modarresi-Ghazani, F., WenHua, L., \& XiaoHui, Z. (2018). Chlorogenic acid (CGA): A pharmacological review and call for further research. Biomedicine and Pharmacotherapy, 97(August 2017), 67-74. https://doi.org/10.1016/j.biopha.2017.10.064

Pati, S., Losito, I., Palmisano, F., \& Zambonin, P. G. (2006). Characterization of caffeic acid enzymatic oxidation by-products by liquid chromatography coupled to electrospray ionization tandem mass spectrometry. Journal of Chromatography A, 1102(1-2), 184-192. https://doi.org/10.1016/j.chroma.2005.10.041

Poupard, P., Guyot, S., Bernillon, S., \& Renard, C. M. G. C. (2008). Characterisation by liquid 
cnromatograpny coupıed to electrospray ionısation lon trap mass spectrometry or pniorogiucinoı and 4-methylcatechol oxidation products to study the reactivity of epicatechin in an apple juice model system. Journal of Chromatography A, 1179(2), 168-181. https://doi.org/10.1016/j.chroma.2007.11.083

408 409

411 Wong-Paz, J. E., Muñiz-Márquez, D.

D. B., Aguilar,

C. N., Sotin, H., \& Guyot, S. (2015). Enzymatic 297(124932). https://doi.org/10.1016/j.foodchem.2019.05.206 synthesis, purification and in vitro antioxidant capacity of polyphenolic oxidation products from apple juice. LWT - Food Science and Technology, 64(2), 1091-1098. https://doi.org/10.1016/j.lwt.2015.07.007

\section{Figure 1}


423

$424 \quad$ Figure 2

425

426

427

428<smiles></smiles>

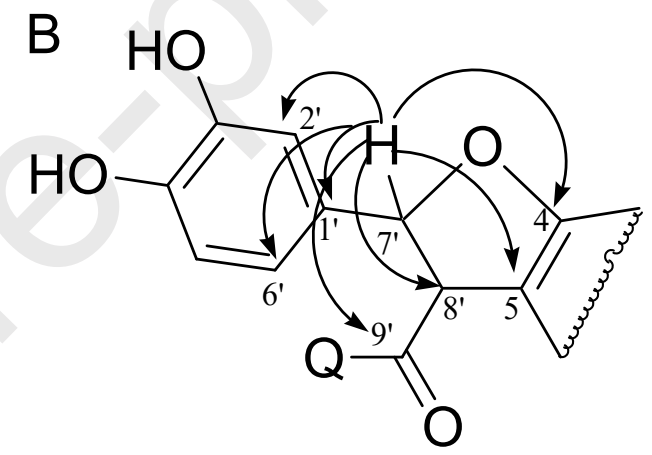

429

430

431

$432 \quad$ Figure 3

433

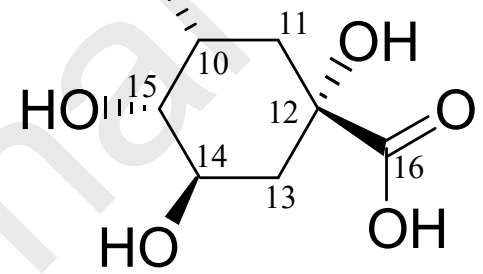



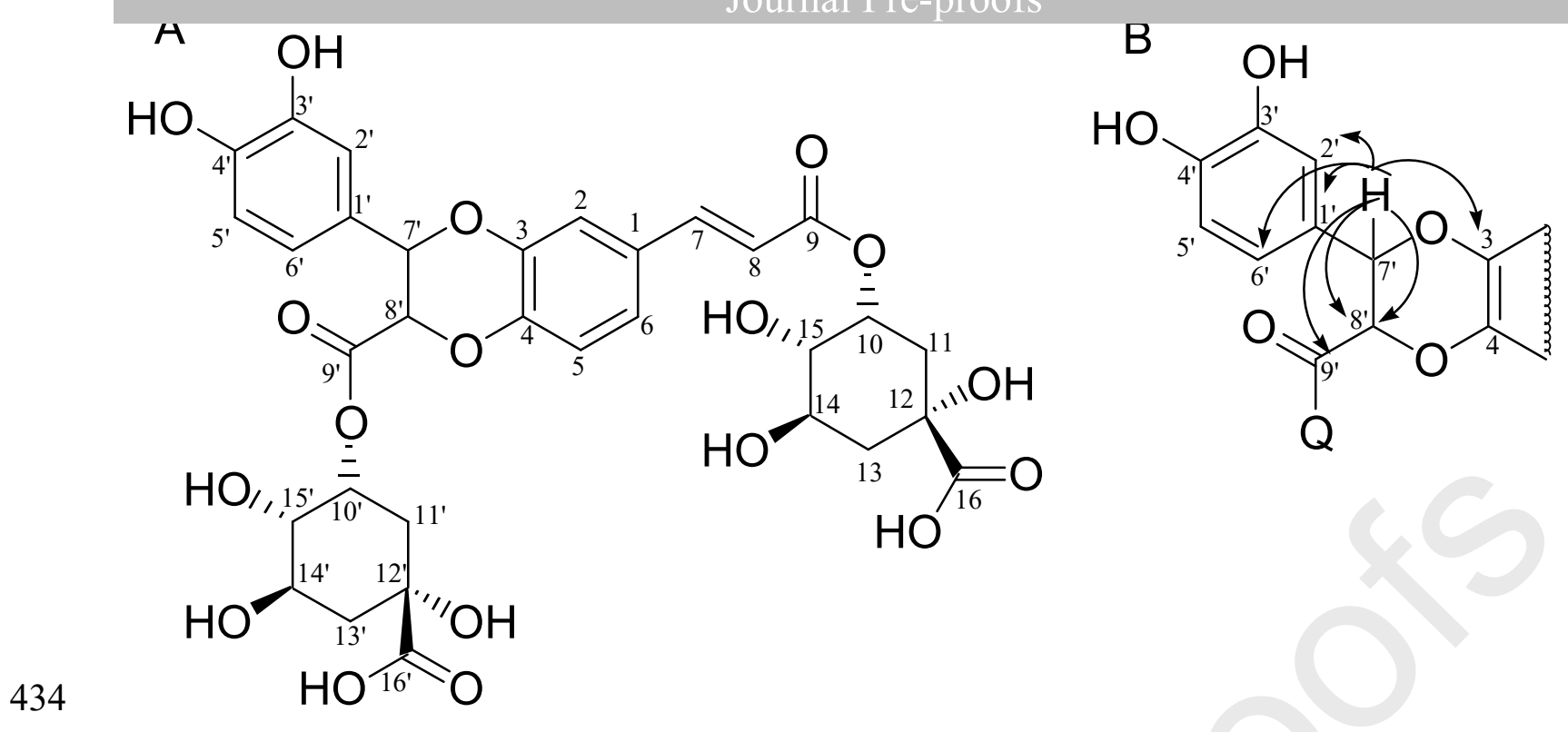

Figure 4

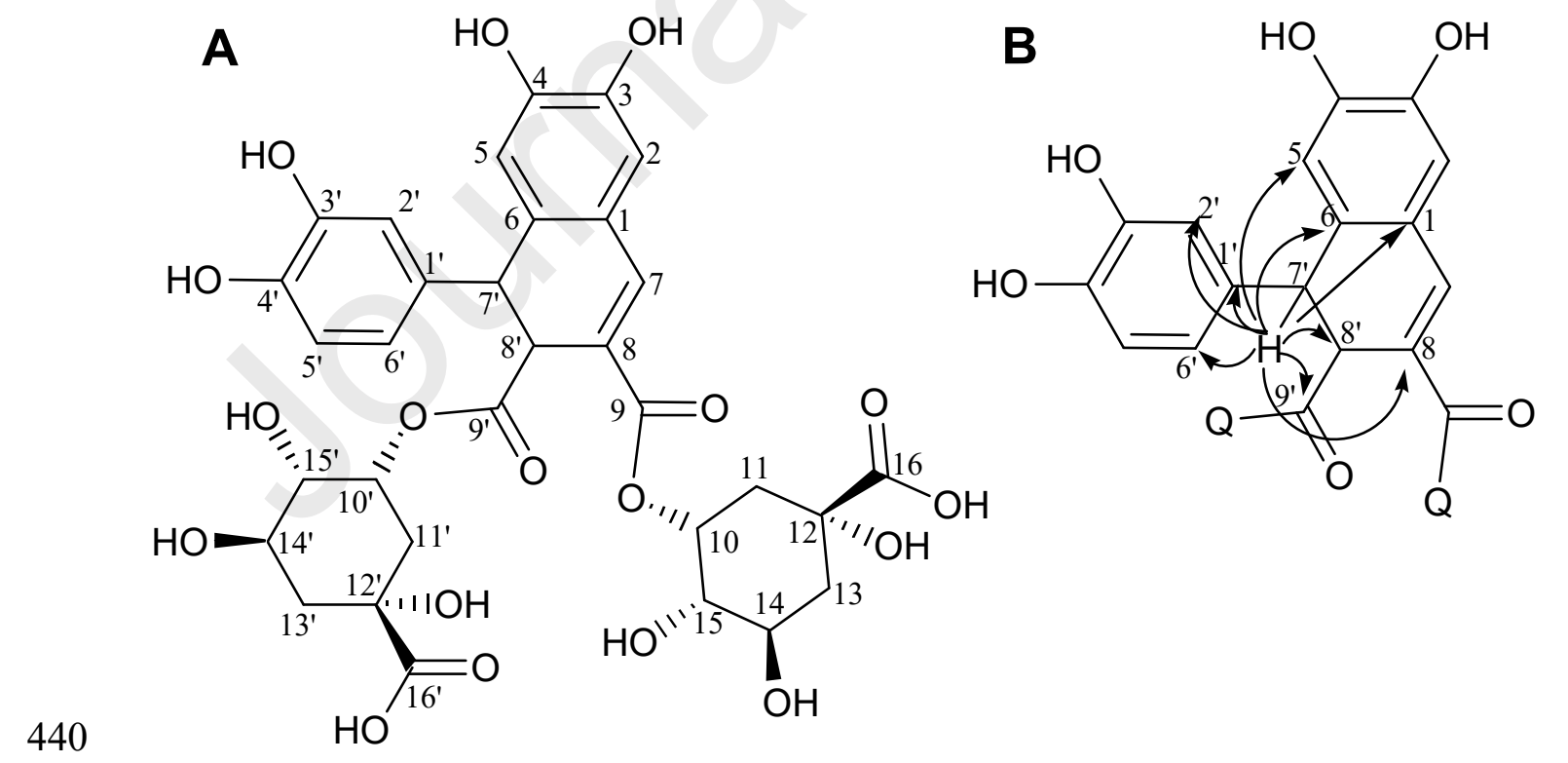




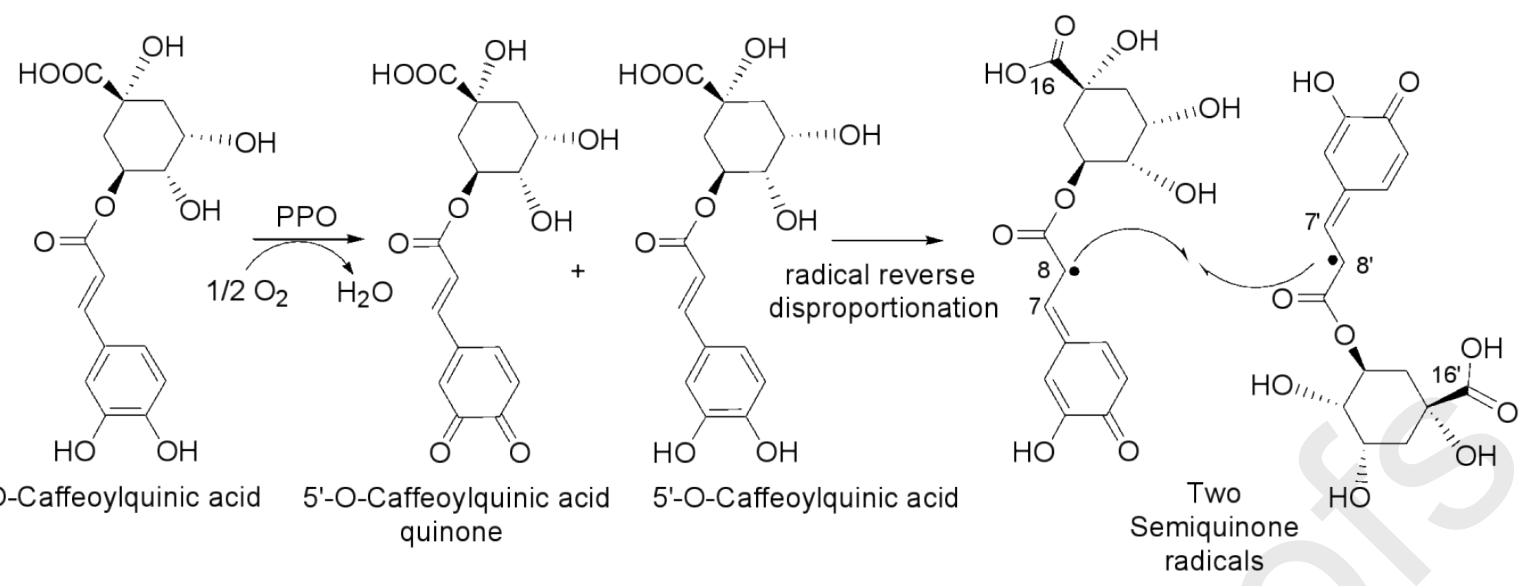

705-2 Hypothesis A
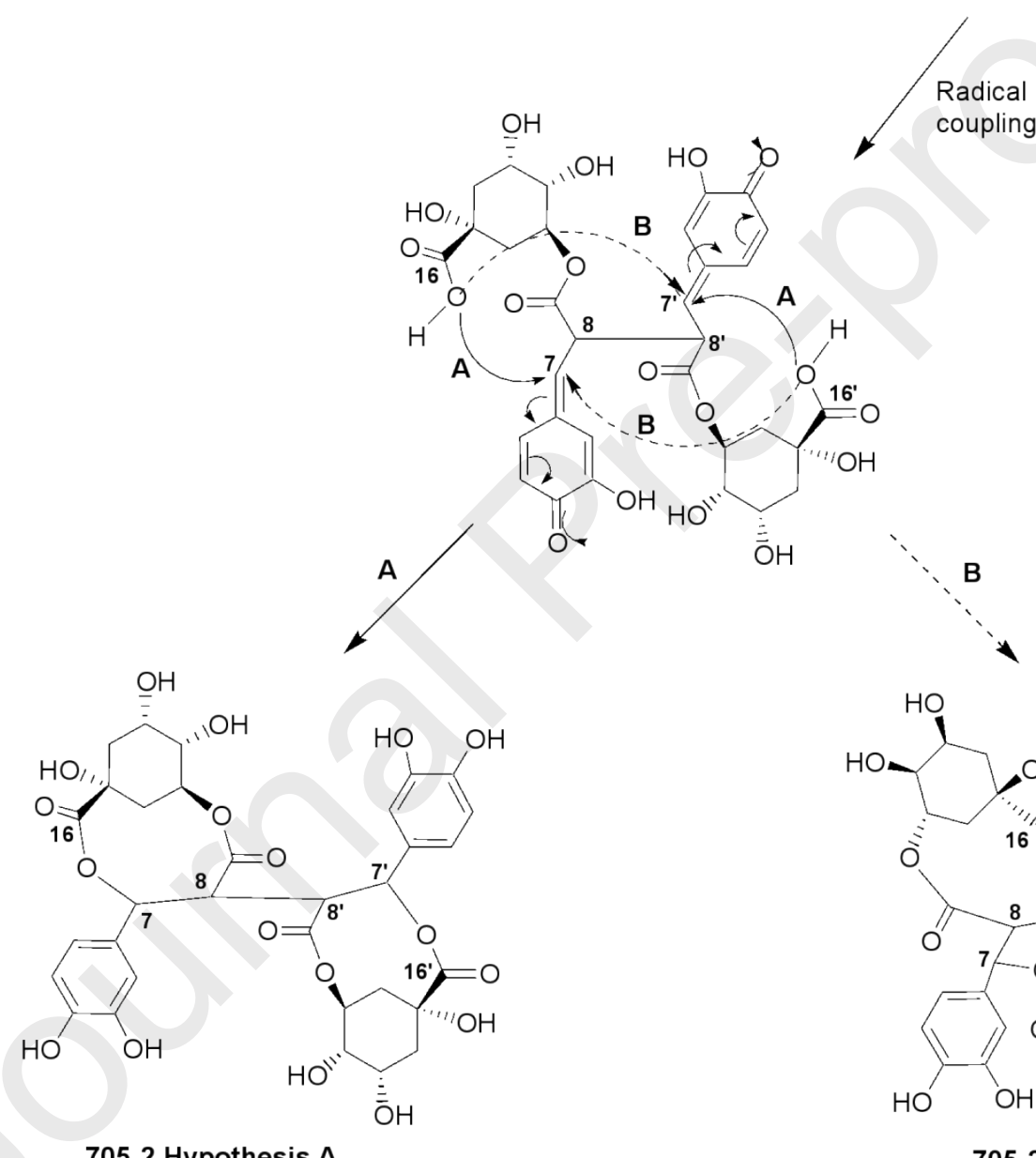

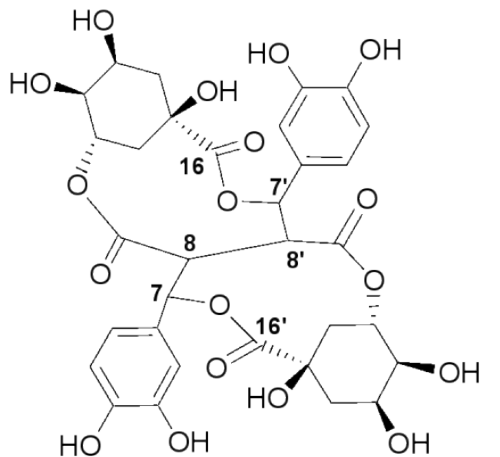

705-2 Hypothesis B 
448 containing CQA oxidation products (706 Da).

Figure 2. A: Structure of products 705-3 and 705-4 corresponding to dehydrodicaffeoylquinic acids showing a dihydrobenzofuran-type structure; B: HMBC correlations of proton $\mathrm{H}^{\prime}$ ' where $\mathbf{Q}$ is quinic acid moiety.

Figure 3. A: Structure of products 705-5 and 705-6 corresponding to dehydrodicaffeoylquinic acids showing a dihydrobenzodioxan-type structure; B: HMBC correlations of proton $\mathrm{H}^{\text {' }}$ ' where $\mathbf{Q}$ is a quinic acid moiety.

Figure 4. A: Structure of products 705-1 and 705-1.1 corresponding to dehydrodicaffeoylquinic acids showing a dihydronaphthalene-type structure; B: HMBC correlations of proton $\mathrm{H}^{\prime}$ ' where $\mathbf{Q}$ is a quinic acid moiety.

Figure 5. Proposed mechanisms for the formation of two hypothetical structures corresponding to 463 product $705-2$.

466 Table 1. Chemical shifts of protons $\left({ }^{1} \mathrm{H}\right)$ and carbon $\left({ }^{13} \mathrm{C}\right)$ for the seven CQA dehydrodimers 467 analysed.

\begin{tabular}{|c|c|c|c|c|c|c|c|c|c|c|c|c|c|c|c|c|c|c|c|c|}
\hline \multirow{2}{*}{ Position } & \multicolumn{4}{|c|}{$705-1$} & \multicolumn{4}{|c|}{ 705-1.1 } & \multicolumn{4}{|c|}{$705-2$} & \multicolumn{4}{|c|}{ 705-3 } & \multicolumn{4}{|c|}{$705-4$} \\
\hline & $\delta \mathrm{C}$ & $\delta \mathbf{H}$ & M & $\mathbf{H z}$ & $\delta \mathrm{C}$ & $\delta \mathbf{H}$ & $\mathbf{M}$ & $\mathbf{H z}$ & $\delta \mathrm{C}$ & $\delta \mathbf{H}$ & M & $\mathbf{H z}$ & $\delta \mathrm{C}$ & $\delta \mathbf{H}$ & M & $\mathbf{H z}$ & $\delta \mathrm{C}$ & $\delta \mathbf{H}$ & $\mathbf{M}$ & $\mathbf{H z}$ \\
\hline 1 & 125,81 & - & - & - & 125,8 & - & - & - & 131,4 & - & - & - & 128,45 & - & & $\begin{array}{lll}- & - \\
\end{array}$ & 128,52 & - & - & - \\
\hline 2 & 118,06 & 6,88 & $\mathrm{~s}$ & - & 118,17 & 6,87 & $\mathrm{~s}$ & - & 121,9 & 6,77 & - & - & 116,06 & 7,06 & $\mathrm{~d}$ & 1,5 & 116,16 & 7,05 & $\mathrm{~d}$ & 1,3 \\
\hline 3 & 146,48 & - & - & - & 146,42 & - & - & - & 147,2 & - & - & - & 141,64 & - & - & - & 141,5 & - & - & - \\
\hline 4 & 150,05 & - & - & - & 150,06 & - & - & - & 148,1 & - & - & - & 149,36 & - & - & - & 149,24 & - & - & - \\
\hline 5 & 118,16 & 6,56 & $\mathrm{~s}$ & - & 117,85 & 6,5 & $\mathrm{~s}$ & - & 117,3 & 6,77 & - & - & 126,2 & - & - & - & 126,33 & - & - & - \\
\hline
\end{tabular}




\section{Journal Pre-proofs}

$132,37 \quad-\quad-\quad-\quad 132,62$

$116,9 \quad 6,83$

$\begin{array}{lllcccc}116,62 & 7,21 & \text { dd } & 1.2, & 1.2 & 116,96 & 7,36\end{array}$

$140,9 \quad 7,65$

$\begin{array}{llllllll}141,1 & 7,63 & \mathrm{~s} & - & 73,5 & 6,3 & \mathrm{dd} & 11 ;\end{array}$

$145,27 \quad 7,62$ d 15,9

$145,4 \quad 7,63$ d $\quad 15,9$

123,68

124,12

$55,3 \quad 3,89$ dd $11 ;$

$114,78 \quad 6,35 \quad$ d $\quad 15,9$

$114,81 \quad 6,39 \quad \mathrm{~d}$

15,9

169,18

169,03

171,4

10

$73,51 \quad 5,32$ td $9.0 ; \quad 75,7 \quad 4,72 \quad m$

167,09

167,07

$73,37 \quad 5,32$ td $\begin{gathered}9.4 ; \\ 4.3\end{gathered} \quad 73,51 \quad 5,32$ td $\begin{gathered}9.0 ; \\ 4.5\end{gathered}$

$75,7 \quad 4,72 \quad \mathrm{~m} \quad \mathrm{nd}$

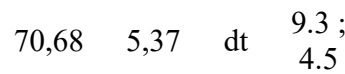

$70,72 \quad 5,37 \quad \mathrm{dt} \quad 8.5$

$11 \quad 39,89 \quad \begin{array}{ll}2.27 \\ 2.07\end{array} \mathrm{~m} \quad$ nd

$\begin{array}{ll}39,62 & 2.22 ; \\ 2.11 & \mathrm{~m}\end{array}$ nd

$31,6 \begin{array}{cc}2.53 \\ 1.75\end{array} \mathrm{~m} \quad$ nd

77,14

74,5

$37,44 \begin{array}{ccc}2.26 \\ ; & \mathrm{m} & \\ 2.10 & & \end{array}$

2.23

74,81

$37,15 \quad ; \quad \mathrm{m} \quad \mathrm{nd}$ 74,56

$13 \quad 39,08 \begin{gathered}2.19 \\ 2.07\end{gathered} ; \mathrm{m} \quad$ nd $\quad 39,05 \quad \begin{array}{ccc}2.20 ; \\ 2.06\end{array} \mathrm{~m} \quad \mathrm{nd}$

14

2.20

$2.20-2.20$

$39,3 \quad 1.77$ dt 14 ,

$\begin{array}{lccc}36,86 & ; & \mathrm{m} & \mathrm{nd}\end{array}$

$\begin{array}{llll}36,8 & ; & \mathrm{m} & \mathrm{nd}\end{array}$

$68,3 \quad 3,97$ dt $\begin{array}{r}2.2 \\ 3.5\end{array}$

69,94 4,2 m nd

$69,55 \quad 4,18$

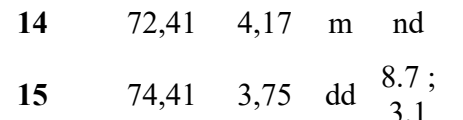

$72,27 \quad 4,18 \quad \mathrm{~m} \quad$ nd

$69,4 \quad 3,39$

$72,1 \quad 3,77$ dd 9.5 ;

$71,704 \quad 3,76 \quad-$ 177.96

178,07

or

172,7

175,77

175,66

178.07

131,4

136,89

136,18

$121,9 \quad 6,77$

131,78

131,6

$116,82 \quad 6,48 \quad$ d $\quad 2,1$

$117,16 \quad 6,53 \quad$ d $\quad 2,1$

147,2

$112,58 \quad 6,86 \quad$ d $\quad 1,5$

$112,54 \quad 6,86 \quad-\quad 1,5$ 146,94

147,01

147,2

145,27

145,27

$145,91 \quad-\quad$ -

146,1

148,1

145,45

145,48

$117,11 \quad 6,65 \quad$ d $\quad 8,1$

$117,16 \quad 6,68$ d $\quad 8,1$

$117,3 \quad 6,77$

$114,97 \quad 6,79 \quad \mathrm{~d} \quad 8,1$

$\begin{array}{lll}115 & 6,79 & -\end{array}$

$121,03 \quad 6,45$ dd 8.1 ;

$121,47 \quad 6,49$ dd 8.1 ;

$116,9 \quad 6,83$

$47,52 \quad 4,47 \quad$ d $\quad 3,4$

$48,26 \quad 4,38$ d 5,6

$73,5 \quad 6,3$ dd 11 ;

$117,34 \quad 6,79$ dd $\begin{array}{r}8.1 ; \\ 1.5\end{array}$

$\begin{array}{lll}117,31 \quad 6,79 & -\quad 8.1 ; \\ & 1.5\end{array}$

$86,96 \quad 6,05 \quad \mathrm{~d} \quad 7$

$87,17 \quad 6,04 \quad$ d $\quad 7$

$50,1 \quad 3,94 \quad$ d $\quad 3,4$

$\begin{array}{llll}50,3 \quad 3,97 & \text { dd } \quad \begin{array}{c}5.5 \\ 0.7\end{array}\end{array}$

$55,3 \quad 3,89$ dd 11 ;

$\begin{array}{llll}55,65 & 4,37 & \text { d } & 7\end{array}$

$\begin{array}{llll}55,97 & 4,37 & \text { d } & 7\end{array}$

174,8

175,43

171,4

170,57

170,5

$10^{\prime}$

$73,65 \quad 5,17$ td $\begin{gathered}9.4 \\ 4.6\end{gathered}$

$75,7 \quad 4,72 \quad \mathrm{~m} \quad \mathrm{nd}$

$71,92 \quad 5,43$ dt 9.9 ;

$72,07 \quad 5,39 \quad \mathrm{dt} \quad 9.8$;

$11^{\prime}$ 2.06 ;

$39,62 \quad 2.01 ;$
1.83 $\mathrm{~m} \quad$ nd

$\begin{array}{lll}31,6 & 2.53 ; \\ 1.75\end{array} \mathrm{~m} \quad \mathrm{nd}$

$\begin{array}{llll}37,95 & 2.2 ; & 2.1 & \mathrm{~m}\end{array} \mathrm{nd}$

75,08

2.21

$37,54 \underset{2.06}{;} \mathrm{m} \quad \mathrm{nd}$ 77,18 74,5

14

$39,32.57 ; \mathrm{dt} ; 2.8$;

$\begin{array}{llll}36,86 & 2.2 ; \quad \mathrm{m} \quad \mathrm{n}\end{array}$

74,82

13

$\begin{array}{lc}2.14 ; \\ 39,08 & 2.03\end{array} \mathrm{~m} \quad$ nd $\quad 38,99 \begin{gathered}2.12 ; \\ 2.03\end{gathered} \mathrm{~m} \quad \mathrm{nd}$ $\begin{array}{ll}1.77 \mathrm{dt} & 14, \\ & 2.2\end{array}$

$68,3 \quad 3,97$ dt $\begin{array}{r}11.7 \\ 3.5\end{array}$

$70,45 \quad 4,17$

$69,4 \quad 3,39$

$72,46 \quad 3,79$ dd 9.5 ;

172,7

175,77

or

\section{8}

469

M: Multiplicity

470 
Seven caffeoylquinic acid (CQA) dehydrodimers were analysed ${ }^{1} \mathrm{H}$ and ${ }^{13} \mathrm{C}$ NMR

Four molecular skeletons of caffeoylquinic acid (CQA) dehydrodimers were elucidated

Six compounds exhibited dihydrobenzofuran, benzodioxane or dihydronaphtalene nuclei

A new CQA dehydrodimer showing a symmetric dicatechol skeleton was identified.

Two structure hypotheses were formulated for this new molecule identified.

\section{CRediT authorship contribution statement}

Claudia Mariana Castillo-Fraire: Investigation, Methodology, Writing - original draft. Sandrine Pottier: Investigation, Writing - Review \& Editing. Arnaud Bondon: Investigation, Writing - Review \& Editing. Pascal Poupard: Supervision, Validation, Writing - review \& editing. Erika Salas: Supervision, Writing - Review \& Editing. Stéphane Bernillon: Investigation. Sylvain Guyot: Supervision, Conceptualization, Writing - review \& editing. 